\title{
Estimated GFR (eGFR) by Prediction Equation in Staging of Chronic Kidney Disease Compared to Gamma Camera GFR
}

\author{
Mohammad Masum Alam', Md. Mozammel Hoque², Shamim Momtaz Ferdousi Begum³ ${ }^{3}$, Naila Atik Khan ${ }^{4}$. \\ 'Research Assistant, Department of Biochemistry, BSMMU. ${ }^{2}$ Professor, Department of Biochemistry, BSMMU. ${ }^{3}$ Professor, National Institute of \\ Nuclear Medicine and Allied Sciences, BSMMU. ${ }^{4}$ Research Assistant, Department of Biochemistry, BSMMU,
}

\begin{abstract}
:
Background: Glomerular filtration rate is an effective tool for diagnosis and staging of cluronic kidney disease. The effect of renal insufficiency by different method of this tool among patients with CKD is controversial. Objective: The objective of this study was to evaluate the performance of eGFR in staging of CKD compared to gamma camera based GFR. Methods: This cross sectional analytical study was conducted in the Department of Biochemistry Bangabandhu Sheikh Mujib Medical University (BSMMU) with the collaboration with National Institute of Nuclear Medicine and Allied Sciences, BSMMU during the period of January 2011 to December 2012. Gama camera based GFR was estimated from DTPA renogram and eGFR was estimated by three prediction equations. Comparison was done by Bland Altman agreement test to see the agreement on the measurement of GFR between three equation based eGFR method and gama camera based GFR method. Staging comparison was done by Kappa analysis to see the agreement between the stages identified by those different methods. Results: Bland-Altman agreement analysis between GFR measured by gamma camera, CG equation ,CG equation corrected by BSA and MDRD equation shows statistically significant.CKD stages determined by CG GFR, CG GFR corrected by BSA, MDRD GFR and gamma camera based GFR was compared by Kappa statistical analysis. The kappa value was $0.66,0.77$ and 0.79 respectively. Conclusions: This study findings suggest that GFR estimation by MDRD equation in CKD patients shows good agreement with gamma camera based GFR and for staging of CKD patients, eGFR by MDRD formula may be used as very effective tool in Bangladeshi population.
\end{abstract}

Keywords: eGFR, Gamma camera GFR, Chronic kidney disease staging.

[BSMMUJ 2015;8(I) : 44-49]

\section{Introduction:}

Chronic kidney disease (CKD) is a progressive loss in kidney over a period of months or years. Often, chronic kidney disease is diagnosed as a result of screening . CKD may also be identified when it leads to one of its recognized complications .'

Incidence of renal disease increases with age due to progressive loss of nephron mass in every mammalian species . ${ }^{2}$ Glomerular filtration rate (GFR) describes the flow rate of filtered fluid through the kidney. ${ }^{3}$ All individuals GFR $<60 \mathrm{ml} / \mathrm{min} / 1.73 \mathrm{~m}^{2}$ for 3 months are classified as having $\mathrm{CKD}$, irrespective of the presence or absence of kidney damage .'

Address for Correspondence: : Dr. Mohamınad Masum Alam Research Assistant, Biochemistry Department, BSMMU, Dhaka. E-mail address: dr.masum@yahoo.com
According to The National Kidney Foundation-Kidney Disease Outcome Quality Initiative (NKF-K/DOQI) guidelines CKD is classified into 5 stages.

Stage 1 ,Kidney damage with normal or relatively high GFR ( $\geq 90 \mathrm{ml} / \mathrm{min} / 1.73 \mathrm{~m} 2 .{ }^{\prime}$ Stage 2, Mild reduction in GFR (60-89 ml/min/1.73 m2) with kidney damage.' Stage 3, Moderate reduction in GFR $(30-59 \mathrm{ml} / \mathrm{min} / 1.73$ $\mathrm{m} 2$ ). British guidelines distinguish between stage $3 \mathrm{~A}$ (GFR 45-59) and stage 3B (GFR 30-44) for purposes of screening and referral. ${ }^{4}$ Stage 4 , Severe reduction in GFR (15-29 $\left.\mathrm{ml} / \mathrm{min} / 1.73 \mathrm{~m}^{2}\right)$. Stage 5, Established kidney failure $\left(\right.$ GFR $<15 \mathrm{ml} / \mathrm{min} / 1.73 \mathrm{~m}^{2}$ )

Glomerular filtration rate is a commonly accepted standard measure of renal function. The generally accepted gold-standard technique for GFR assessment is inulin infusion. ${ }^{5}$ This technique is difficult and time-consuming 
to perform and is therefore regarded as inappropriate for routine clinical use. As the GFR cannot be measured easily in clinical practice, several equations have been developed to estimate GFR." NKF-K/DOQI and Kidney Disease Improving Global Outcomes (KDIGO) guidelines recommend the estimation of GFR (eGFR) using those prediction equations based on serum creatinine.

The most commonly used prediction equations are the 4 variables Modification of Diet in Renal Disease $(\mathrm{MDRD})^{7}$ and Cockcroft-Gault $(\mathrm{CG})^{8}$ equations. Procedures using radiopharmaceuticals, especially Tc- $99 \mathrm{~m}$ DTPA (diethylenetriaminepentaacetic acid), have been proposed as rapid, less invasive, and reliable options for estimating GFR by gamma camera renogram. ${ }^{9}$

A first major criticism with the CKD staging system has surrounded the accuracy of the eGFR estimates using the MDRD or CG equation especially at higher levels of true GFR (>60 $\mathrm{mL} / \mathrm{min} / 1.73 \mathrm{~m} 2$ ). While estimates using the MDRD equation at GFR below $60 \mathrm{~mL} / \mathrm{min} / 1.73 \mathrm{~m}^{2}$ demonstrate low levels of bias and high levels of precision. It is clear that as true GFR increases above 60 $\mathrm{mL} / \mathrm{min} / 1.73 \mathrm{~m}^{2}$, the equation underestimates the GFR, leading to misclassification of subjects with $\mathrm{CKD} .^{10}$

According to the NKF-K/DOQI guidelines chronic kidney disease in children and adolescents, the estimates of glomerular filtration rate (GFR) are the best indices of the level of kidney function, and the creatinine clearance using timed urine collections do not improve the estimated GFR over that provided by prediction equations. $^{\text {"1 }}$

In general MDRD formula has shown better predictive performance than the Cockcroft-Gault equation ${ }^{12}$ but it underestimate the number of patients with declining function. $^{13}$

However, neither of these currently available estimating equations has been validated thoroughly in the South Asian population. The applicability of these equations and the factor for ethnicity to South Asians, including Bangladeshi population, is therefore unknown. ${ }^{14}$
The aim of this study is to evaluate a camera-based method for estimation of GFR at the same time as obtaining a renogram in the staging of $\mathrm{CKD}$. Such a method would add convenience to evaluation of renal function in routine clinical practice. We also examined the relative accuracy of GFR determined by the Cockcroft-Gualt, MDRD equation and compared them with GFR obtained by using a sampling DTPA renogram method (as a reference).

\section{Methods:}

This cross sectional analytical study was conducted in the Department of Biochemistry, Bangabandhu Sheikh Mujib Medical University (BSMMU) with the collaboration with National Institute of Nuclear Medicine and Allied Sciences, BSMMU. Ethical clearance for the study was taken from the central ethical committee, BSMMU. A number of $75 \mathrm{CKD}$ patients selected by non probability purposive sampling from the nephrology division, NINMAS, BSMMU during the period of January 2011 to December 2012.

Whole procedure was briefed to the participants and written consent was be taken. All were allowed to take breakfast and proper hydration was ensured before giving IV isotope. Dynamic sequential images of both kidneys were obtained in the posterior position immediately after IV administration of $5 \mathrm{mCi}$ dose of $99 \mathrm{~m}$ Tc-DTPA and study continued for 10-30 min. Measured DTPA GFR was done by modified Gates method 15 from renogram. With all aseptic precautions $5 \mathrm{ml}$ blood sample was drawn from the antecubital vein to measure serum creatinine for eGFR. GFR was measured by CG equation, Corrected CG equation, MDRD formula and by DTPA renogram. Subjects were then categorized into 5 stages according to their GFR by different method. Comparison was done by Bland Altman agreement test to see the agreement on the measurement of GFR between three equation based eGFR method and gama camera based GFR method. Staging comparison was done by Kappa analysis to see the agreement between the stages identified by those different methods. A k value near to be 1 was considered as statistically significant. 


\section{Results:}

A total 75 CKD patients of both male and female were enrolled in the study to find out measured GFR by 99mTc-DTPA. At the same time GFR was estimated by using serum creatinine base equations; MDRD, CG formula and CG corrected by body surface area . Staging of the CKD patients by GFR according to different method were done. Demographic and other factors influencing GFR were also considered in the study procedure and study outcome.

\section{Table -I}

GFR $\mathrm{ml} / \mathrm{min}$ in different methods of study population.

\begin{tabular}{lll}
\hline Method & Mean \pm SD & Range \\
\hline DTPA GFR & $64.72 \pm 25.39$ & 14.60 to 126.90 \\
MDRD GFR & $60.40 \pm 23.62$ & 13.00 to 118.60 \\
CG GFR & $63.17 \pm 29.60$ & 8.80 to 129.80 \\
Corrected CG GFR & $64.50 \pm 24.75$ & 13.20 to 119.50
\end{tabular}

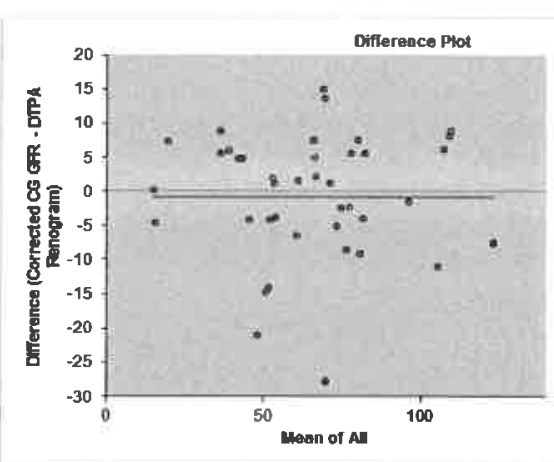

Fig-1 : Bland-Altman Plotting of DTPA renogram GFR and Corrected $C G$ GFR where $95 \%$ limits line range is small.

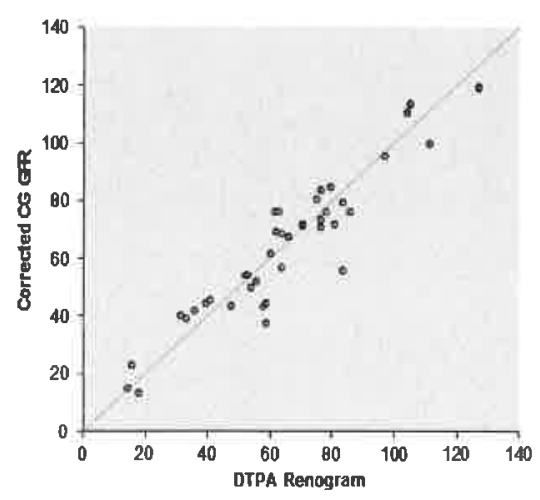

Fig-2: Bland-Altman scatter plot of DTPA renogram GFR and Corrected CG GFR.

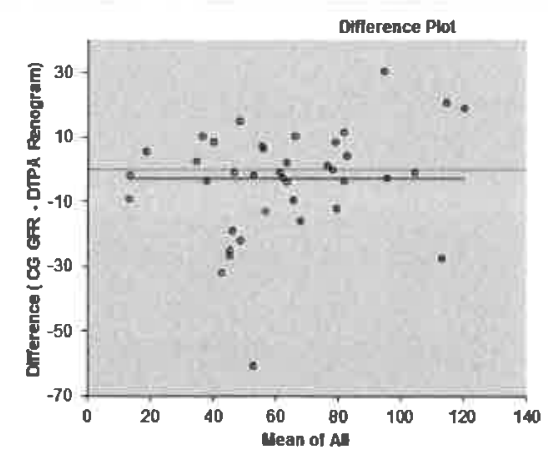

Fig-3: Bland-Altman Plotting of DTPA renogram GFR and CG GFR shows $95 \%$ limits line range is wide.

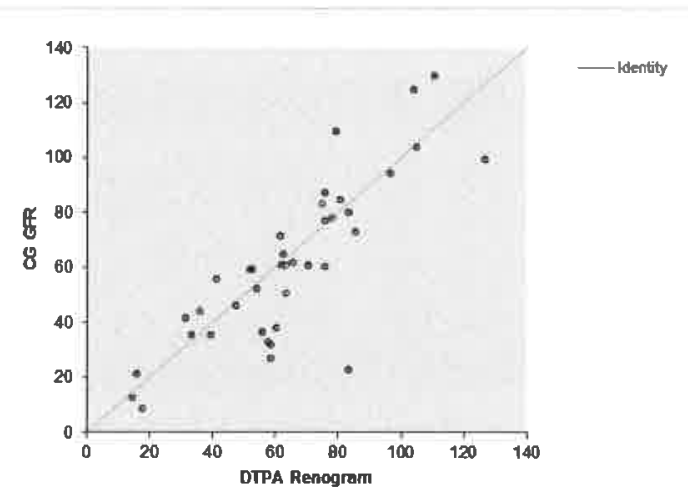

Fig-4 : Bland-Altman scatter plot of DTPA renogram GFR and $C G$ GFR.

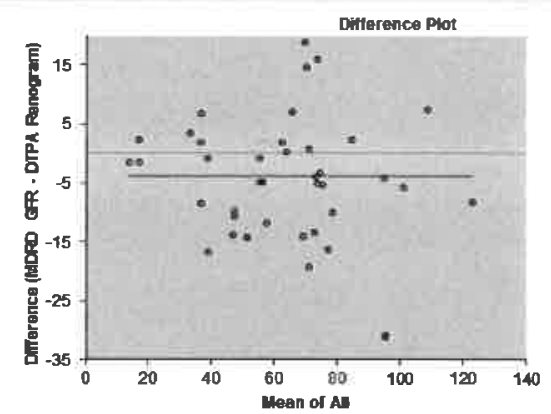

Fig-5 : Bland-Altman Plotting of DTPA renogram GFR and MDRD GFR shows $95 \%$ limits line range is small.

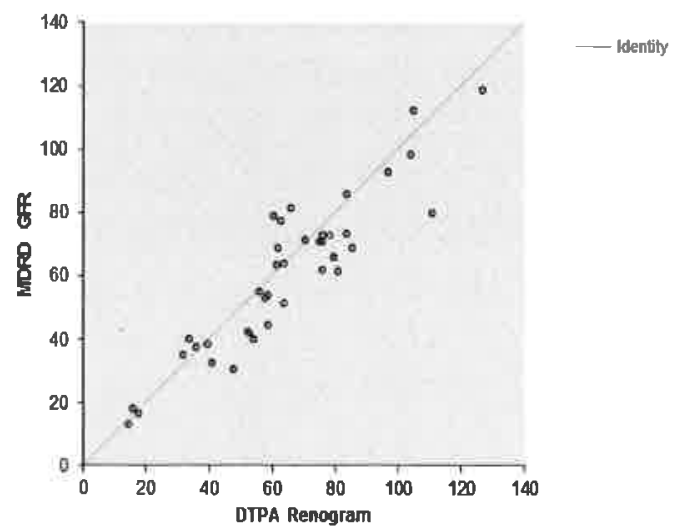

Fig-6: Bland-Altman Plotting of DTPA renogram GFR and MDRD GFR. 
Table -II

Kappa agieement $(k=0.66)$ benteen diferent stages of $C K D$ deternined by $D T P A$ renogram $G F R$ and $C G G F R$

\section{CG GFR}

DTPA Stage Stage Stage Stage Stage Stage Total k $\begin{array}{llllllll}\text { GFR } & 1 & 2 & 3 \mathrm{~A} & 3 \mathrm{~B} & 4 & 5 & \text { value }\end{array}$

\begin{tabular}{lllllllll}
\hline Stage 1 & 10 & 0 & 0 & 0 & 0 & 0 & 10 & \\
Satge 2 & 4 & 28 & 1 & 2 & 0 & 0 & 35 & \\
Stage 3A & 0 & 0 & 6 & 6 & 2 & 0 & 14 & \\
Stage 3B & 0 & 0 & 2 & 8 & 0 & 0 & 10 & .66 \\
Stage 4 & 0 & 0 & 0 & 0 & 3 & 2 & 5 & \\
Stage 5 & 0 & 0 & 0 & 0 & 0 & 1 & 1 & \\
Total & 14 & 28 & 9 & 16 & 5 & 3 & 75 & \\
\hline
\end{tabular}

\section{Table-III}

Kappa agreement $(k=0.77)$ between different stages of $C K D$ determined by DTPA renogram GFR and corrected $C G$ equation based GFR

\section{Corrected CG GFR}

DTPA Stage Stage Stage Stage Stage Stage Total k

$\begin{array}{llllllll}\text { GFR } & 1 & 2 & 3 \mathrm{~A} & 3 \mathrm{~B} & 4 & 5 & \text { value }\end{array}$

\begin{tabular}{lllllllll}
\hline Stage 1 & 10 & 0 & 0 & 0 & 0 & 0 & 10 & \\
Satge 2 & 0 & 34 & 1 & 0 & 0 & 0 & 35 & \\
Stage 3A & 0 & 0 & 7 & 7 & 0 & 0 & 14 & \\
Stage 3B & 0 & 0 & 2 & 8 & 0 & 0 & 10 & .77 \\
Stage 4 & 0 & 0 & 0 & 0 & 3 & 2 & 5 & \\
Stage 5 & 0 & 0 & 0 & 0 & 0 & 1 & 1 & \\
Total & 10 & 34 & 10 & 15 & 3 & 3 & 75 &
\end{tabular}

\section{Table -IV}

Kappa agreement $(k=0.79)$ between different stages of CKD patients determined by DTPA renogram GFR and $M D R D G F R$

\section{MDRD GFR}

DTPA Stage Stage Stage Stage Stage Stage Total k

$\begin{array}{llllllll}\text { GFR } & 1 & 2 & 3 \mathrm{~A} & 3 \mathrm{~B} & 4 & 5 & \text { value }\end{array}$

$\begin{array}{lllllllll}\text { Stage 1 } & 8 & 2 & 0 & 0 & 0 & 0 & 10 & \\ \text { Satge 2 } & 0 & 34 & 1 & 0 & 0 & 0 & 35 & \\ \text { Stage 3A } & 0 & 0 & 6 & 8 & 0 & 0 & 14 & \\ \text { Stage 3B } & 0 & 0 & 0 & 10 & 0 & 0 & 10 & .79 \\ \text { Stage 4 } & 0 & 0 & 0 & 0 & 5 & 0 & 5 & \\ \text { Stage 5 } & 0 & 0 & 0 & 0 & 0 & 1 & 1 & \\ \text { Total } & 8 & 36 & 7 & 18 & 5 & 1 & 75 & \end{array}$

\section{Discussion:}

Progression to kidney failure or other adverse outcome could be prevented or delayed by early detection and treatment of CKD. ${ }^{16}$ The Glomerular Filtration Rate (GFR) is considered the best overall index of kidney function in healthy and diseased condition. ${ }^{17}$ Since dialysis and kidney transplantation is too costly for a large number of people, early detection, staging and intervention are the only cost effective strategies for CKD treatment. $^{18}$

In this cross sectional study, our aim was to asses staging of CKD patients by e GFR and gamma camera based GFR, then evaluation of the eGFR staging compared to the staging of gamma camera based GFR. In our study we measured e GFR by CG formula, CG formula corrected by BSA and MDRD equation.

Our Result in our stady demonstrate the GFR estimated by predictive equations are significantly close to that measured by $99 \mathrm{mTc}-\mathrm{DTPA}$ isotope method. DTPA renogram GFR and Corrected CG GFR shows 95\% limits line from -18.54 to 17.06 in Bland-Altman Plotting. Here bias is about -0.738 and difference versus average is about 0.06 . Scatter plot shows good correlation. DTPA renogram GFR and CG GFR shows $95 \%$ limits line from -37.63 to 31.64 in Bland-Altman Plotting, where bias is about -2.99 and difference versus average is about 0.08 and scatter plot also shows good correlation. Another Bland-Altman Plotting of DTPA renogram GFR and MDRD GFR shows $95 \%$ limits line are about -23.871 to 16.015 , bias is about -3.928 and difference versus average is about 0.27 . In this case scatter plot also shows good correlation. Kappa agreement statistical analysis between different stages of CKD determined by DTPA renogram GFR with CG GFR, CG GFR corrected by BSA and MDRD GFR was done. 
The kappa value was $0.66,0.77$ and 0.79 respectively . These kappa values indicate good agreement.

Our study results are in consistent with various previous investigations in the literature. A study reported that the MDRD equations were more accurate within $30 \%$ and $50 \%$ of the measured GFR compared with the CG GFR methods. ${ }^{19}$ Al-Wakeel et al. also found that the GFR estimated by the MDRD predictive formula equation revealed the best correlation with measured GFR by DTPA renogram. ${ }^{20}$ Serum cystacin $\mathrm{C}$, serum creatinine , reciprocal of cystacin $\mathrm{C}$, and reciprocal of serum creatinine were inferior to the MDRD and Cockcroft-Gault predictive formulas in estimating GFR in Saudi patients with CKD and after renal transplantation. ${ }^{21}$

Some studies also differ from our study for instance the MDRD formula is considered unsuitable for Asians ${ }^{22}$ while it is accurate for Chinese. ${ }^{23}$ Another study reported that the MDRD formula better per formed in the worse stage of CKD than the Cockcroft-Gault formula. ${ }^{24}$ In 2007, Ma em $\neg$ phasized that the application of these formulas was necessary in the different ethnic populations and a modified MDRD formula was necessary to fit for the Chinese population. ${ }^{23}$ Earlier 2005 others found that MDRD equa $\neg$ tion overestimated GFR in patients with CKD stages 4 and 5, while it underestimated GFR in CKD stage $1 .{ }^{25}$

However we can draw attention from the present study that $\mathrm{CKD}$ staging by MDRD, CG corrected by BSA are reliable and can be use for eGFR which provide a guide to the nephrologists and physicians of Bangladesh to monitor the progression of renal diseases and to guide the possible management plan in our patients. The MDRD equation which can be calculated easily by using a computer device and also the CG and CG GFR equation which is easy to calculate is recommended for use in Bangladeshi CKD patients for disease staging until further studies in this field come out with stronger evidence against their use.

\section{Conclusion:}

From this study we may conclude that GFR estimation by
MDRD equation in CKD patients shows good agreement with gamma camera based GFR and eGFR by MDRD formula may be used as very effective tool for staging of $\mathrm{CKD}$ patients in Bangladeshi population.

\section{References:}

1. National Kidney Foundation 2002. "K/DOQI clinical practice guidelines for chronic kidney disease". Retrieved 2008-06-29.

2. Grauer GF, Glomerulonephritis. Semin, Vet Med Surg. Small Anin 1992; 7: 187-97.

3. Stevens LA, Coresh J, Greene T, Levey AS. "Assessing kidney function--measured and estimated glomerular filtration rate". The New England Journal of Medicine 2006;354 (23):2473-83.

4. National Institute for Health and Clinical Excellence. Clinical guideline 7, Chronic kidney disease, London 2008.

5. Delpassand ES, Homayoon K, Madden T. Determination of glomerular filtration rate using a dual-detector gamma camera and the geometric mean of renal activity: correlation with the Tc- $99 \mathrm{~m}$ DTPA plasma-clearance method. Clin Nucl Med 2000 vol ;25(4):258-62.

6. Levey AS, Bosch JP, Lewis JB, Greene T, Rogers N, Roth D. A more accurate method to estimate glomerular filtration rate from serum creatinine: a new prediction equation. Modification of Diet in Renal Disease Study Group. Ann Intern Med 1999;130:461-70.

7. Levey AS, Greene T, Kusek JW, Beck GL. A simplified equation to predict glomerular filtration rate from serum creatinine. J An Soc Neplurol 2000;11:155A

8. Cockcroft DW, Gault MH. "Prediction of creatinine clearance from serum creatinine". Nephron 1976;16(1): 31-41.

9. Stacy BD, Thorbum GD. Chromium-51 ethylenediaminetetraacetate for estimation of glomerular filtration rate. Science 1966;152(725): 1076-77.

10. Coresh J, Stevens LA. Kidney function estimating equations: where do we stand? Curr Opin Nephrol Hypertens $2006 ; 15: 276$ 84.

11. Hogg RJ, Furth S, Lemley KV, Portman R, Schwartz GJ, Coresh J, et al. National Kidney Foundation's Kidney Disease Outcomes Quality Initiative clinical practice guidelines for chronic kidney disease in children and adolescents: evaluation, classification, and stratification. Pediatricsn 2003; 111:1416-21.

12. Poge U, Gerhardt T, Woitas RP. Calculation of glomerular filtration rate using serum cystatin $\mathrm{C}$ in kidney transplant recipients. Kidney Int 2006;70:1878.

13. Gera M, Slezak JM, Rule AD, Larson TS, Stegall MD, Cosio FG. Assessment of changes in kidney allograft function using creatinine-based estimates of glomerular filtration rate. Am J Transplant 2007; 7:880-87.

14. Matsuo, Imai E, Horio M, Yasuda Y, Tomita K, Nitta K et al.On behalf of the collaborations developing the Japanese equation for estimating GFR. Revised equations for estimating glomerular filtration rate (GFR) for serum creatinine in Japan. Am J Kidney Dis 2009 ; 53: 982-92. 
15. Gates GF. Glomcrular filtration rate: estimation from fiactional renal accumulation of 99m TC DTPA. Am J Radiol 1981; 138: 565 .

16. Locatelli F, Vecchi LD, Pozzoni P. The importance of early detection of chronic kidney discasc. Neplirol Dial Transplant $2002 ; 17: 2-7$

17. Levey AS, Stevens LA, Schınid CH, Christopher H, Schınid P, Zhang $\mathrm{Y}$, et al. A new equation to estimate glomerular filtration rate. Ann Intern Med 2009; 150 (9):604-12.

18. Smith SR, Svetkey LP, Dennis VW. Racial differences in the incidence and progression of renal disease. Kidney Int $1991 ; 40$ : 815-22.

19. Lin J, Knight E, Hogan ML, Singh AK .A comparison of prediction equations for estimating glomenular filtration rate in adults without kidney disease. J Am Soc Nephrol 2003; 14: 2573-80.

20. Al-Wakeel JS, Hammad D, Al-Suwaida AK, Tarif N, Chaudhary $A R$, Insani $A$, et al. Validation of predictive cquations for glomerular filtration rate in the Saudi population. Saudi J Kidney Dis and Trans 2009; 20(6):1030-7.
21. Zuo L, Ma YC, Zhuo YH, Wang M, Xu G.B, Wang HY. Application of GFR-estimating equations in Chinese patients with clronic kidney disease. Am J Kidney Dis 2005; 45: 463-72.

22. Jafar TH. Levey AS, Jafary FH, White F. Gul A, Rahbar MH, et al. Ethunic subgroup differences in hypertension in Pakistan. J Hypertens 2003; $21: 905-12$.

23. Ma YC, Zuo L, Zhang CL, Wang M, Wang RF, Wang HY. Comperison of $99 \mathrm{~m}$ Tc- DTPA renal dynamic imaging with modificd MDRD cquation for GFR estimation in chines patients in different stages of clironic kidney disease. Nephrology Dialysis Transplantation 2007; 22(2): 417-23.

24. Kuan Y, Hossain M, Surman J, El-Nahas AM, Haylor J. GFR prediction using the MDRD and Cockcroft and Gault equations in patients with end-stage renal disease. Nephrol Dial Transplant $2005 ; 20(1): 2394-401$.

25. Vervoort G, Willems HL, Wetzels JF. Assessment of glomerular filtration ratc in healthy subjects and normoalbuminuric diabetic patients: validity of a new (MDRD) prediction equation. Nephrol Dial Transplant 2002; 17: 1909-13. 